\title{
School Choice, School Culture and Social Justice: A Canadian Case Study
}

\author{
David A. Ball \\ Calgary Board of Education \\ daball@cbe.ab.ca \\ Darren E. Lund, Faculty of Education \\ University of Calgary \\ dlund@ucalgary.ca
}

\begin{abstract}
This paper reports on findings from a case study conducted in a public school offering multiple programs of choice. A guiding purpose of the study was to analyze the impact of operating multiple programs of choice in a single school setting on the organizational and lived culture of the school. The urban Alberta school under study offered alternative educational programs in science, Mandarin Immersion, special education and "regular" programs. Multiple methods of data collection followed an ethnographic approach, and included document and policy analysis, field observations, focus groups and semistructured interviews with administrators, parents, teachers and students from each of the programs. The results reported here focus on related themes of equity and social justice related to analyses of school choice, attending specifically to participants' understandings of power and privilege, with policy and practice implications. Themes included social class stratifications, marginalization within advantage, perceptions of disempowerment, fragmented school identity, limitations of choice programs, and perceptions of teaching staff quality.
\end{abstract}

\section{Introduction}

For a variety of economic, political and pedagogic reasons, public education systems in many Western countries have begun experimenting with reform initiatives such as school choice. Aimed at increasing academic achievement and providing parents with education options for their children, school choice has introduced economic market forces to public education. In the Canadian province of Alberta, one result of school choice legislation has been the development of various alternative programs of choice within the public education system from which parents may choose rather than their designated community school. Since 1994, the numbers of private schools, charter schools and public magnet schools have increased significantly (Alberta Education, 2007). The enrollment of students in private, charter, virtual and home schools had grown to 6.7\% of Alberta's students by 2001 (Calgary Board of Education, 2007).

In particular, the locations of charter schools in Alberta have a noticeable pattern, with new schools appearing mainly in the province's urban centers. In the city of Calgary, for example, many programs of choice operate in schools alongside other programs (i.e., schools within schools) resulting in schools operating programs with 
diverse pedagogical mandates. All thirteen of Alberta's charter schools are located in urban centres, with a total enrolment of 7000 students, 80 percent of them in the city of Calgary (Sadava, 2010, p. 29). One drawback of charter schools is that they are difficult to initiate in rural areas due to limited student population and financial resources. There are fewer charter schools in Edmonton, because the public school board in that city anticipated the desire for school choice and responded by creating its own diversity of alternate program choices, thus limiting the potential for charter schools to open (Dosdall, 2001; Edmonton Public Schools, 2007). On the contrary, the Calgary public school board's initial response was to disallow the formation of several alternative programs for which stakeholders had applied. Several of these applications went on to become charter schools-notably, schools with traditional learning, English as a Second Language, gender-specific, science-focused, and gifted education programs. Most of these schools have enjoyed continuous growth in their student populations to the point of reaching full capacity.

\section{Significance and Focus of the Research}

Despite this growing phenomenon, there is little research on the impact of multiple programs on school culture. In particular, questions arise around whether school administrators attempt to create common school culture, in spite of differently mandated programs, or allow programs to operate as separate entities sharing a physical space. There has been extensive scholarly and public debate about school choice issues (for examples, see: Archer, 2005; Ball, 2003; Bosetti, 2005; Brantlinger, 2003; Dingerson, Miner, Peterson, \& Walters, 2008; Gewirtz, Ball \& Bowe, 1995; Sadava, 2010; West, 2006). Much of the literature has focused on the extent of school choice as it relates to the fulfillment of promises, typically only implicitly addressing issues related to social justice and school culture.

Issues of power and privilege are rarely foregrounded in traditional educational policy and programming documentation around school reform, but an increasing number of critical scholars are pressing for discussions of school choice to focus on social justice and equity issues, especially around educational opportunity for disadvantaged students (e.g., Carr \& Lund, 2007; Levine-Rasky, 2008; Lund \& Veinotte, in press; Nieto \& Bode, 2007). As James (2003) asserts, people from dominant cultural groups, whether based on ethnic, racial, linguistic, economic or other identity markers, "come to realize that they have a privileged and prestigious position in society, and, as a result, access to all the social, political and economic institutions within that society" (p. 102). In the case of education, parents from dominant groups have demanded specific alternative programs or charter schools to benefit their children. Critical multicultural and antiracist scholars have long argued that conservative school reforms have caused an "escalated transfer of economic resources and the mobility of capital away from poor communities" (Sleeter \& McLaren, 2009, p. 19), resulting in further disparities between the advantaged and disadvantaged. Analyzing the particular situation with charter schools and other school choice options, Apple (2004) notes that "charter schools and their equivalents.... tend to attract parents who live and work in relatively privileged communities" (p. 27). 
To date, no study has specifically analyzed the impact of operating multiple programs of choice in a single school setting on the organizational and lived culture of the school. The few related graduate studies available have focused on dual-program language immersion schools (Guimont, 2003; Lamarre, 1995) and on understanding the leadership role for public schools operating an alternative program (Crawford, 2003). The research reported here is from a case study of the impact that operating multiple programs has had on an urban public school. This study considered the perceptions of students, parents, teachers and administrators of various aspects of their program and school culture within a formerly under-utilized inner-city school that has experienced the introduction and operation of alternative programs of choice due to the local school board's program renewal process.

Of particular interest were perceptions about their experience of the organizational culture in the school. Deal and Peterson (1999) described the shaping of a school's culture as complex, and the most important challenge facing an administrator. Addressing language immersion programs in a multicultural society, Lambert and Taylor (1984) noted the increased complexity for administration when leading more than one program, as it is "more problematic to implement programmes in such a way that no one group is, or feels, unjustly treated in the process" (p. 211). Literature on culture from sociological and organizational fields offered a conceptual background for the study, including work on national cultures in organizations. Additionally, we drew on research based on educational and equity markets (Brantlinger, 2003; Brighouse, 2000; Gewirtz, Ball \& Bowe, 1995), culture in dual-program schools (Gaskell 1995; Guimont, 2003), and alternative program leadership (Crawford, 2003), among other relevant work.

\section{Research Questions}

Although school choice has prompted vigorous debate, the main focus has been on examining schools offering a single choice. For example, charter schools are typically organized to fulfill the objectives of a single mission, such as gender-specific or a specified pedagogy. Magnet schools in the United States also have a particular mandate and usually reside in one school exclusively. From a survey of alternative programs locations in Alberta's two main cities, it appears they often share a school building with other programs such as a regular neighbourhood program (Calgary Board of Education, 2007; Edmonton Public Schools, 2007). It is unclear from official information whether the mixture of programs is due to economies of scale, or an intentional matching of groups.

In Canada, the organization of dual program schools is not new, as language immersion programs, particularly French immersion, have existed since the 1960s alongside regular English language programs (Crawford, 2003). However, a relatively recent development precipitated by Alberta's school reform package has resulted in multiple programs running simultaneously in a school. There remains a need to examine the benefits and challenges for shaping a strong, cohesive school culture when multiple programs coexist in a building. Alternative programs are meant to meet the aggregate individual needs of the students within the program, so there may be tension between cultural aspects of particular programs and a cohesive school culture. The overarching purpose of this project was to conduct a case study of a school culture that has multiple program offerings. 
The guiding questions for the research were as follows:

1. What is the impact of multiple programs on a school culture?

2. How do school administrators manage shaping a cohesive school culture with multiple programs in operation?

3. How are social justice concerns, in terms of student diversity, reflected in the culture of a multi-program school?

4. How are pedagogical innovation and teacher collaboration experienced in the culture of a multi-program school?

5. How do student and parent stakeholder experiences reflect the culture of a multiprogram school?

Further details on the entire results of the study may be found in Ball (2007), while this article will focus primarily on the results and analyses associated with the third research question that focused on social justice concerns. For reasons of space and for the coherence of our focus, other issues emerging from the data are not presented here.

\section{Method: Selecting a Case Study Approach}

The study employed a combined qualitative methodology of a case study following the tenets of ethnography, as described by Creswell (2007) and Yin (2003), as the most appropriate way to investigate the research questions. With its roots in anthropology, ethnography is a research tradition used, as Cresswell (2007) explains, to describe and interpret the meanings of behavior, language and interactions of a culturesharing group. Within the tradition, the researcher is immersed in the daily lives of the people in the group as a participant observer for a prolonged period of time.

Observational impressions are triangulated using semi-structured interviews with key informants from the group. The primary researcher, David Ball, was a teacher with eight years of public school experience who had taken a paid study leave to conduct the research full-time. The other author, Darren Lund, has 16 years of public school teaching experience and is an academic researcher with an interest in social justice. In this study, key informants were sought from stakeholder groups from each program in the school, including students, parents, teachers and administrators.

A school site in an urban centre in Alberta, which we are calling Riverview School, was identified as representative of a public school operating multiple, diverse educational programs, and interested in achieving a common one-school culture. Within the school, the primary researcher conducted six weeks of observations, including two weeks during which a purposeful sample of students, parents and teachers from each program, along with school administrators, was selected to be interviewed using semistructured interview guides. In all, transcripts of twenty-two interviews and eight focus group discussions were analyzed.

Perceptions of teacher and administrator stakeholders were gathered voluntarily through semi-structured individual interviews. Sixteen teachers and two administrators from a variety of ages and teaching experience demographics were sought from each of the programs in operation. Focus group interviews were used to gather perceptions from parent and student stakeholder groups to encourage comfort and idea generating capacities (Denzin \& Lincoln, 2003). Twenty-three students participated in groups assembled by program, age level, and gender balance; due to the vulnerability of the 
special education program, these students were not interviewed. Seventeen parents participated in groups assembled by program. Both student and parent groups were ethnically diverse, but socioeconomic status and family income and other demographic details were not made available by the school district.

The research site is located in an inner-city urban neighbourhood with a relatively lower socioeconomic status (SES) profile and shifting demographics. The neighbourhood has not kept pace with the city's general growth in education, income and proportion of school-aged children. Data were gathered for the regular community program, the two alternative programs of choice (Science Program and Mandarin Immersion Program) and a small special education program that functioned independently.

At Riverview School the Regular Program has operated for nearly 100 years, a special education program for at least 25 years, the Mandarin Program for six years and the Science Program for three years. Despite having the majority of students enrolled, the Science Program was still considered as emergent because of its continued, rapid growth and development towards consistent programming. About 75 percent of the student body was enrolled in the Science Program, 20 percent in the Mandarin Program, and 5 percent in the Regular Program. Students in the Mandarin and Science Programs enrolled by choice and tended to travel from across the city to attend. Of demographic note is 95 percent of the Mandarin Program students were ethnically of East Asian origin. The Regular Program students resided in the local neighbourhood and were designated to the school. Students in the special education program were assigned to the school from across the city by senior administration. Teachers in the Mandarin, Science and the special education programs were hired according to specific skill sets necessary to teach in a particular alternative program. Of demographic note is that all teachers in the Mandarin program were ethnically Chinese; all teachers but one were born and educated in East Asia. Only five out of 30 teachers had been in their current positions for more than three years, with two-thirds having been there for less than two years. The Principal was one of the architects of the Science Program, undertook its initial administrative helm, and was also responsible for administering the other programs.

\section{Findings for Research Question 3: Social Justice Concerns}

Social class stratifications: Advantages for the already privileged. The original study's third research question investigated social justice concerns. To begin, program fees were much higher for the alternative programs of choice than the Regular Program. While 60 percent of Regular Program students had subsidized or unpaid fees, fewer than 15 percent of Science Program students at Riverview School fell in those categories. This indicates a much higher degree of financial affluence among Science Program students' families. Nearly 40 percent of Mandarin Program students had had their fees subsidized, but only two percent (one family) left their fees unpaid. A high percentage of Mandarin Program families were eligible for subsidized fees, but had the cultural capital required to choose the program, and to securing funding for their children to attend.

The parents drawn to these specialized alternative programs within charter and public school settings are typically advantaged in some specific cultural and economic ways. Certainly, interviews with parents indicated they used a variety of rationalizations regarding their children's need for a special program, while questioning the wisdom of allowing priority enrollment to go to neighbourhood students. A parent in the Science 
Program talked about the reaction to the remaining community students being offered spots in the Science Program rather than moving schools:

There was quite a furor when they [offered preferred spots] because science parents chose to be here and they expected a certain level of ability, and there was a worry that it was going to drag down the level quite dramatically. Another parent from the Science Program commented that, "it's almost always the community kids that are causing the problems on field trips or in the class." Some of the Science Program teachers also expressed concern over prioritizing neighbourhood student access; one teacher noted that by allowing the Regular Program students into the Science Program, "you end up with a class when you're trying to get deep into a concept and then you've got the same kids being yahoos, disrupting everything. So, I don't think we're going to have a filter, but it's not right that we won't." Another teacher in the Science Program said, "there's a huge element of elitism among parents. With the alternative program, the parents think their kid is doing something extra special that is beyond the community school and, therefore, their kid is more special than the neighbourhood kids."

Interview data with students at Riverview School supports other research suggesting a correlation between lower SES families who have chosen the Science Program, and their tendency to do so based on physical proximity to home, rather than strong program interest (Ball \& Reay, 1997). Several of the students interviewed were having mixed success, but expressed interest in staying with the program. Because their teachers felt there was a connection between some of their disruptive students and their neighbourhood residency, the stated perception of a correlation added an element of elitism to the program. Further, the students in the Regular Program talked about feeling undervalued by the adult staff within the school; one student said: "It's not about field trips or technology. It's about feeling thrown in the dark and they're always concentrated on the science school kids... They forget about us, it feels like." Observations supported this sense of cultural division. One stark example was that students from the Science and Mandarin programs wore simple, yet distinct, uniforms of khaki pants and navy or white polo shirts. Often, these students carried a variety of personal electronic devices. Community students wore their regular clothes, which often appeared unkempt in comparison. None of these students was observed carrying personal electronic devices, but skateboards were not uncommon. In hallways, teachers seemed more likely to address behaviour issues from the community students rather than similar behaviours of the alternative program students.

Marginalization within advantage. In the case of the Mandarin Program, families seem to possess higher rates of economic and social capital than the Regular Program parents, both in paying their fees and negotiating bureaucracy. Sixty percent of Mandarin Program families paid their fees, compared to 40 percent of Regular Program families. As well, 38 percent of Mandarin Program families applied for, and secured, fee exemptions. A Mandarin Program teacher provided an explanation that many of his students' parents are new to Canada, so they have little money while they learn the language and become established in Canadian society. However, despite their temporary economic status, these families are well educated, see the value in quality education, and are motivated to secure the best education for their children. As well, the Principal 
reported that Mandarin Program parents tend to be tightly knit and communicate informally, which could explain the high degree of fee subsidy application. The strong social network of Chinese families could provide enough social capital with which Mandarin Program parents learn to negotiate the subsidy process, despite language deficiencies. Therefore, they tended to have a higher SES, based on economic, cultural and social capital. Interestingly, only one family defaulted on their payment, perhaps reflecting a cultural characteristic to honour rules.

Unlike the Science Program students, the Mandarin Program students did not wear uniforms, and there was virtually no signage inside or outside of the school recognizing the program's existence in the building. In this case, the hierarchies of advantage placed these parents and students in a less privileged position within this school. According to some members of the school community, there was a strong feeling that the program did not enjoy the same status within the school environment. A Mandarin Program student observed:

It seems like we're second choice compared to the science school. They get more access to the technology than we do. We never use the laptops and the one time we did, they said we overbooked them, so they got the laptops. We've had them once this year.

Another Mandarin Program student noted the inequity in the distribution of technology in the school, saying, "it always seems all the money goes to the science school. Like look at the big TV at the front of the school. What does that show? It just shows off more of their trips and says, wow, look at us. If someone can give some of that money to us, it would be better."

A common sentiment among the school population is that the Science Program involves more innovative pedagogy that should be emulated by all staff. As one Mandarin Program teacher said: "Everything that we read and discuss is about the Science Program. I'm trying to change, but we've taught this way [teacher-centered] for 500 years.... The traditional Chinese way must have something good because it's been around so long. I'm trying to find a balance." This person suggested that when there is a dominant program in the school, its existence clearly seems to devalue the philosophy, pedagogy and practice of the other programs of choice. Evidence of this is in the priority placed on providing much-needed school space to the Science Program to the detriment of the other programs. One Mandarin Program student said, presciently:

I think we'll get squeezed out next year. I think this will be the last year. They need more space for the Science Program and there are always notices to discuss the Mandarin Program. When our program moved in, we had needed to expand our space, so we slowly got driven out of our last school. So, what's happening to us there will happen to us again.

It is noteworthy that this Mandarin Program had already moved schools two times in the past, and one year after the conclusion of this research, six of the nine grades were relocated once again to another school.

Second class citizens: Perceptions of disempowerment. Riverview School's alternative programs do not represent the SES make-up of the wider community; the school under study is located in a relatively disadvantaged neighbourhood. Local community parents regularly expressed their sense of inequity in the treatment of their children. One Regular Program parent said: 
The community kids were just set aside. There's no final dance or ceremony or anything. They're just resigned to the fact. It's ground them down over the years. They don't feel like they have any voice in anything... They see the changes too; it's not their old school anymore.

Likewise, a teacher shared her observations of the remaining community students since the addition of the new Science and Mandarin Programs:

Our Regular Program kids lost their feeling of safety. They had a feeling that here, in this building, they were safe. Who knows what our students went home to, but then this new program comes in with their little blue shirts and their tan pants and that feeling of security was gone.

Another teacher expressed the privileged position that the Science Program seemed to hold in the school, also making reference to the school uniforms:

As well, the science school wears uniforms, so that sets them apart from the Regular Program. They're out on field trips all the time. The Regular Program kids didn't really go on any field trips. It wasn't expected of the Regular Program. As well, there are the field trip fees that are paid up front. So there was the perception that they didn't get the same attention and [the principal] favoured the science school over the Regular Program kids.

The frequent use of the term "science school" to refer to just one program in the building also reflects an unspoken positioning of that alternative program as the preferred defining identity of the school as a whole.

Teachers were not the only members of the school community to sense this inequity between programs. Some of the students attending school in the Regular Program also expressed their perceptions at their program's lower status in the school, and in the larger community. One student said:

I don't really think the Regular Program fits in that much. Since we're the last Regular Program class, I guess, they just think the whole school is science school now. When they advertise the school, they always say, it's the science school at Riverview. They don't say anything about the Regular Program. Regarding the school administration and teaching staff, one Regular Program student said, "it's like they don't care about us." Another student said, "I feel like a second-class citizen here. That's exactly how I feel." A Science Program student echoed that sentiment with this observation about her program compared to the Regular Program students: "We get more chances to do activities and it's kind of like we forgot about them." Clearly there are complex social tensions at play in any pluralistic school, but when the existing programs - and students - are divided along geographic, racialized and economic lines, the points of division become more salient.

Fragmented school identity: Dissolving of community. The devaluing of the local community's students, the perceived privileging of some programs over others, and their tenuous status in the school's social and pedagogical hierarchy led to a strong sense of fragmentation and loss of community. One Regular Program teacher noted:

I don't think there's a strong sense of community in the whole school. I think there's a strong sense of community in pockets of the school. There's a lack of connection with the kids coming into the school from so many different universes. 
With families all over the city, it'd be difficult for the kids to develop that sense. It might be possible, but I don't know.

The practice of busing children from around the city to alternative programs works against the nostalgia some people appear to hold about community schools that draw local families together in a common community-based enterprise. One Science Program parent expressed reservation on the alternative program model as a whole:

I'm torn about designating a special program in the first place that tears apart communities and schools in the first place. I question the idea of a school that has kids coming from far away and the more a city like [this one] has schools like that, the fewer the community schools there are. There isn't much in my home community that draws us together as a community of citizens. I used to know everyone in the community because we all went to the same school. The lack of community schools is not moving us in a good direction, and I'm part of the problem because I'm sending my child here.

A science student talked about the upcoming closure of the Regular Program:

I can see why they're closing [the Regular Program]. They might just want one big program. I also don't agree with it because some kids from around the block that don't want to be in the Science Program, and they won't really fit and the Regular Program would be a better fit, but because there's no Regular Program, they'll be pushed inside the Science Program where they'll fall behind or disrupt the class.

A Science Program teacher expressed frustration with what he suggested was a lower interest and ability level in the local students, and intimated that they did not belong in the specialized program, saying: "Frankly, if you're going to have a special program, then it can't be home to kids who just happen to live here. There are other schools nearby to accommodate students not interested in science." In social areas such as the playground or in the hallways, students rarely appeared to cross program boundaries when peer grouping. There was no overt hostility observed between groups.

Previously noted social class stratification also served to undermine the development of a cohesive school community, as many students noted the wealth and status distinctions that divided students. One Regular Program student said:

Some of the other grades act snooty because they think they're better than us. It's just the science school kids, they glare at you and act better than you. I know a lot of the science school kids are wealthy. They talk about it. Like on the [Science] trip one said, "Oh yeah, I just paid for it myself." They brag about how big their houses are, and some of my friends have visited them and say their houses are big and they have all these nice things.

Another Regular Program student talked about her awareness of apparent class differences between geographic regions in the city, and how these can be expressed through student behaviour:

The science school kids are kind of snobby. They don't really live in the neighbourhood. They live far away, so I don't know them from the neighbourhood. Some of them are from the neighbourhood and I knew some of them in elementary, but then they went to science school, and that's when they started acting better than you. 
For one Regular Program student, there was a distinct experience of condescension from the Science Program students toward those in other programs; he said: "For some people, they kind of talk down to you, like they're better than you. They kind of treat you like you're stupid." There are social class divisions across Canadian society, so observing them manifested in school cultures was not surprising, but the imposition of a clearly hierarchical regime of alternative programs appeared to create additional divisiveness among staff and students along economic lines.

Limitations of choice programs. Regular and Science Programs are ethnically diverse, but the Mandarin Program is mostly ethnically homogeneous. The homogeneity seems to be a result of the program's mandate rather than selective enrollment. Despite the advertised mandate of the Mandarin Program being for any student interested in learning the Mandarin language, in practice it has attracted mainly immigrant Chinese students with English as a Second Language, and first-generation Chinese students with proficiency in Mandarin. A result of this ethnic homogeneity may be the limited new enrollment of non-Chinese students. Since the current enrollment is comprised of nearly all Asian students, it may be intimidating for non-Asian students to enroll as new students with limited knowledge of Mandarin.

Regarding students with special needs, the Mandarin Program has few, which is partly due, according to the Principal, to ethnic values that resist diagnoses of special needs. This confirms research showing programs of choice inevitably have fewer students with special needs (e.g., Gewirtz, Ball, \& Bowe, 1995). Contrary to these findings, the Science Program enrolls more students than expected with special needs. Possible reasons for this include the Principal's support of equitable access policies of the school board, parents "program hopping" to find a place where their children fit, and identifying the pedagogical mandate of the program matches appropriate learning strategies for their children's special needs-each of which are indicators of high cultural capital, and reflect a high value placed on education.

The special education program's mandate is to address the learning needs of students placed in the program with severe cognitive and developmental needs, so they were not considered using the same parameters as the other programs. It is a program designated for students with special needs regardless of their ethnic or SES characteristics. However, it is interesting to note that parents of special education students expressed frustration with having limited choices available to them for their children. Rather than experiencing a sense of marginalization within the school, parents expressed perceptions they were marginalized within the school system, having to take whatever program and school location was assigned to them.

\section{Perceptions of quality of teaching staff}

Teachers were hired for the Regular Program from the city's public board of education system human resource pool, but it is noteworthy that, following this study, nearly every Regular Program teacher transferred out of the school within three years, and eventually the Regular Program was closed permanently. Likewise, as mentioned above, the bulk of the Mandarin Program was transferred to another school one year after the conclusion of this research. 
One Science Program teacher expressed the perceived differences between resources for the programs, including teaching staff:

This last [remaining Regular Program] group has given in, not given in, but accepted the science school, but if you talk to them, they still have a perception that the Science School gets stuff that they don't get. That was a huge perception when they came in. Suddenly, we're getting computers and LCD projectors and the big TV by the front door. All this stuff is coming in and it's all for science school. They got to use it, but the Regular Program teachers didn't know how to access the technology, so that's more why they didn't get to use it.

There existed a pervasive notion that the Regular Program teachers were somehow less specialized and perhaps less skilled than the specially selected teachers recruited for the higher status programs. Observations of classroom practice supported these perceptions. Science Program teachers were more likely to employ current promising practices such as experiential and/or inquiry learning. Mandarin and Community Program teachers primarily used teacher-centred practices that were heavily reliant on textbooks.

\section{Discussion}

Emerging from the data collected on school programs of choice, and the review of existing literature around social justice concerns, the following issues need further attention. First, school boards have the responsibility to address equity issues around lower SES group under-representation in alternative programs. These findings support research that correlates enrollment in school choice programs with middle and higher SES groups (e.g., Apple, 2004; Brantlinger, 2003; Gewirtz, Ball, \& Bowe, 1995). If the provincial Ministry of Education intends to continue developing and promoting school choice, the government must do more to promote school choice for all of the province's students, not just the economically advantaged. As one Science Program teacher expressed it:

Restricting access goes against the grain of public education, though. It's an interesting dilemma. We're an alternative program so what makes us alternative? Our philosophy makes us alternative, but... public education is for everyone, and this type of education can benefit everyone.

Many urban public school boards, including the one managing the school in this study, have policies that address equity as a foundational tenet for program renewal, and there are measures in place to subsidize fees for disadvantaged students. These policies of equity and fee subsidy are voluntary and positive, since the provincial government does not require them. However, given the low enrollment of disadvantaged families in this school's programs of choice relative to the Regular Program, the policies seem inadequate in achieving equitable enrollment of different SES groups, and are not reflected in the lived practice.

Overall, our findings support other research suggesting that alternative programs of choice attract students from higher SES groups (Ball, 2003; Gewirtz, Ball, \& Bowe, 1995). The inequity of SES group representation in high status programs of choice, such as the Science Program, seems to stem from three causes. The first involves the nature of school choice in Alberta. As policies currently function, parents and students must actively research educational program possibilities, assess their suitability and navigate the enrollment process. This necessity for action by parents and students is not typical of 
lower SES groups (Gewirtz, Ball, \& Bowe, 1995), nor is it likely, due to the cultural/social capital required to access these sources of information. As such, program choices tend to appeal to the advantaged SES groups, since parents from these groups are the most likely to make alternative school choices. As Levine-Rasky (2008) found in a single-school case study, the more affluent parents she interviewed were more likely to be protective of their perceived need to ensure that their own students received a high quality program in the face of changing demographics. She explained that, "emerging from their claims upon school as a private choice, the parents were anxious to 'protect' their children to the neglect of the needs of other children" (p. 464). Policies and practices need to be implemented that aim to remedy the requirement for high cultural capital to access school choices.

Second, the inequity of SES group representation in programs of choice seems a reflection of the educational value different SES groups place on education. These findings concur with other research (e.g., Brantlinger, 2003; Gewirtz, Ball \& Bowe, 1995). As Ball and Reay (1997) outline, for disadvantaged families, education choices are often sought based on physical proximity or convenience. For more affluent families, educational choice is regarded as a means to educational advantage, which will translate into socioeconomic advantage as children enter adulthood. Advantaged families tend to be better educated, so they value education more, and will seek what they regard as the "best" education available within the public system (Levine-Rasky, 2008).

Disadvantaged families do not seem to pursue the "best" education possible, but claim satisfaction with regular programming offered in their community school, no matter its quality, since there is a sense of security in remaining in their home neighbourhood. As well, other obstacles may exist for disadvantaged families to choose alternative programs related to forms of capital, such as the additional cost of fees, a social network to become familiar with available choices, and transportation issues. If these families increase the value they place on education, insist on quality education in their schools, and voice their desires for the education market of program choices, this will improve public education as a whole.

The third cause for the inequity of SES group representation in programs of choice is economic. Staff and students alike shared perceptions and experiences of fiscal inequities at the school, both in the allocation of resources across programs, and in the social relationships within the building. These findings echo theory suggesting school choice acts as a new type of hierarchical social sorting (Kymlicka, 1996; Moore \& Davenport, 1989). Regarding school fees, if public systems provide for equity through bursaries or fee waivers for student and transportation fees, this loss of capital needs to be budgeted system-wide. Currently, the provincial government does not reimburse public school systems for providing waivers to disadvantaged students.

Further, alternative programs often cost more to operate, due to increased student fees to cover enhanced instructional and transportation costs. Under current policy, the local school board needs to approve alternative programs' requests for additional fees specific to the program, such as field studies funds or art supplies. As a result, if particular schools grant subsidies or waivers for these fees, the financial loss must be managed within the school budget. Therefore, if an alternative program were successful in attracting a greater socioeconomic diversity, it might financially compromise its ability 
to deliver the program. Fundraising, lowering expenditures, or increasing program fees for the families would be options, all of which may distract from the pedagogical work, diminish program integrity, or defeat the purpose of providing for equity. In sum, if provincial governments value school choice, they need to develop policies to address socioeconomic inequities existing within that system.

\section{Implications and Recommendations}

Program choice information could be made more accessible to families without social and cultural capital to negotiate web-based material, such as through brochures in disadvantaged schools. Enhanced services for counseling families through program choices could improve the selections parents and students currently make. Fee subsidy and exemption processes should be widened for families with low financial, social and/or cultural capital. Subsidies and exemptions could include student fees, transportation costs, and the cost of uniforms if the program requires them. Also, widening the waiver criteria and financial parameters for families would help. Currently, families need to be receiving social assistance to qualify for fee subsidies, but this does nothing for many disadvantaged families near the official level of "financial hardship."

Further, families requiring financial assistance could use guidance through the paperwork seeking subsidy or exemption. For equitable access, it would be advisable to maintain enrollment priority in alternative programs for local neighbourhood students. However, this policy needs to account for appropriate program choices through an intake process to assess each student's suitability and interest for the program. An intake process should avoid selectively favouring more academically inclined students, and public schools should continue to offer alternative programs of choice in disadvantaged neighbourhoods. This seems to offer some hope in benefiting students from low SES families who may initially value the program because of its close proximity, but soon realize its educational value.

Based on the findings of this study, public school boards are strongly encouraged to follow equity policies regarding special needs students and programs of choice. Although the programs studied here had differing student need profiles, the Science Program administrators showed willingness to enroll students with various learning, emotional and behavioural needs. Although this inclusiveness was a source of tension among some teachers, parents and students, the Principal's opinion that, "we are a public school, and these are our public," reflects an attitude necessary to achieve equity for special needs students within a public system. The provincial government should enact similar policies aimed at equity for special needs students within all publicly funded schools. As identified in this study, there are clear distinctions between the levels of financial commitment to each program, and discrepancies in access to particular alternative programs. Without accompanying financial commitment from the provincial government to acknowledge access and other concerns, equity goals cannot be fully realized.

A more comprehensive study could be undertaken focusing on equity issues involving alternative programs across Alberta and in other provinces. Comparisons of SES, as well as special needs, between students enrolled in alternative programs and regular programs, could reveal the extent to which government policy and district 
practice are successfully managing choice and equity. Most observers assume that school choice in Alberta's public schools will be a continuing policy. As such, funding increases will be necessary to subsidize or offset costs associated with school choice, including necessarily increased transportation, program and other costs. Additional research could be conducted on how these increased costs present challenges with pursuing equity.

Public education in Canada has grown to focus on its inclusive character to build a strong pluralistic democracy, bringing together students from different socioeconomic, cultural, religious, linguistic and ability groups (James, 2003). However, the introduction of market forces seems to have pressured public education to offer school choices appealing to specific private interests. Some of these school choices seem to be diminishing the capacity of public education to build inclusive communities. The findings reported above suggest that school choice appeals mainly to advantaged families searching for "better" education for their children; this relays into additional advantage for their children at public expense, and at the expense of the educational experiences of students in other programs. More public debate needs to happen regarding the role and purpose of public education in Alberta and beyond.

As school choice expands, funding equity needs to be secured for regular community schools. If choosing to attend designated schools is to be recognized as a legitimate choice, policies must be modified to ensure they do not become lower quality schools. Alternative programs are developing a reputation for providing "better" education (Sadava, 2010), a finding echoed in the words of some parents and teachers in this study; however, within a public system, there should never be programs stratified by quality. Policies need to be developed to ensure alternative programs are different by mandate, not quality. In terms of staffing, by adopting teacher profiles outlining specific skill sets required for alternative programs, school administrators have a guideline for transferring teachers out of schools in which their skills may be mismatched, and for hiring more suitable teachers. This human resource practice shows promise as an effective policy for matching teachers with appropriate assignments.

\section{Concluding Remarks}

There are specific implications arising from this research at Riverview School toward developing particular policies and practices impacting the culture in public schools as they evolve to include a greater diversity of program offerings. Significant in these findings is the realization that school culture becomes increasingly complex with the addition of each new program and its culture to the mix of group cultures extant in a school. The importance of developing a shared sense of community without detracting from the integrity of any particular program was also a highlight of the study. A key finding was that school choice in Alberta appeals primarily to families who already enjoy advantages.

Apple (2004) observed that school reforms reveal much about our values as a larger democratic community: "not only is the world deeply unfair but also that schools themselves are prime examples of institutions that simply respond to those who already possess economic and cultural capital" (p. 38). It is problematic that public resources are being allocated to rationalize social advantage for families already advantaged, veiled in the interests of parental choice. As argued above, those parents who now hold social, cultural or racialized advantages are indeed the ones most likely to be taking advantage of 
their choice in schools and school programs. Implications emerge for government policy regarding equity and public education, and for the local school board's long-term program planning.

The complexity of managing a school culture comprised of multiple programs while working towards a common experience was best expressed by the Principal charged with administering it:

I envision programs that meet the learning interests and needs of our groups of students K-9. I have come to understand these learners, both in the Bilingual and Science Programs, as being quite distinct from a regular population of children. I also envision us as a cohesive, vibrant, caring and invigorating community of people working together to foster student learning, personal growth and citizenship in a changing world.

Finding the balance between educational excellence, equity, access and choice is a daunting task, but one that many administrators and educators are willing to strive toward. This work is both political and personal, and inevitably requires a complex balancing of needs and wishes through a critical interrogation of issues of race, class, gender and other issues. Hopefully, this study provides some guidance for negotiating the tension between diversity and cohesion in the ongoing pursuit of more models of choice within public school cultures. Carr (2008) reminds us that our ongoing pedagogical imperative must include "diagnosing, critiquing and taking action to improve the education system, especially with a view to addressing the key concern of social justice" (p. 11). In seeking alternative educational models it is essential to foreground concerns for equity and social justice to ensure the full participation and success of all participants in an educational system that is mandated to serve all students. 


\section{References}

Alberta Education. (2007). School choice. Alberta Education web site. Retrieved August 14, 2010, from http://education.alberta.ca/parents/choice.aspx

Apple, M. W. (2004). Creating difference: Neo-liberalism, neo-conservatism and the politics of educational reform. Educational Policy, 18(1), 12-44.

Archer, J. (2005). An Edmonton journey. Education Week, 24(20), 33-36.

Ball, D. A. (2007). Effects of programs of choice on school culture. Unpublished master's thesis, Graduate Division of Educational Research, University of Calgary, Calgary, AB.

Ball, S. J. (2003). Class strategies and the education market: The middle classes and social advantage. London: RoutledgeFalmer.

Ball, S. J., \& Reay, D. (1997). Spoilt for choice: The working classes and educational markets. Oxford Review of Education, 23(1), 89-101.

Bosetti, B. L. (2005). School choice: Public education at a crossroad. American Journal of Education, 111(4), 435-441.

Brantlinger, E. (2003). Dividing classes: How the middle class negotiates and rationalizes school advantage. London: RoutledgeFalmer.

Calgary Board of Education. (2007). Program choices. Calgary Board of Education web site. Retrieved August 14, 2010, from http://www.cbe.ab.ca/programs/progchoice.asp

Carr, P. R. (2008). The "equity waltz" in Canada: Whiteness and the informal realities of racism in education. Journal of Contemporary Issues in Education, 3(2), 4-23.

Carr, P. R., \& Lund, D. E. (Eds.). (2007). The great white north? Exploring whiteness, privilege and identity in education. Rotterdam, Netherlands: Sense.

Crawford, D. (2003). Above and beyond: Understanding leadership for public school alternative settings. Unpublished doctoral dissertation, University of Calgary, Calgary, AB.

Creswell, J. W. (2007). Qualitative inquiry and research design: Choosing among five Traditions ( $2^{\text {nd }}$ ed.). Thousand Oaks, CA: Sage.

Deal, T., \& Peterson, K. (1999). Shaping school culture: The heart of leadership. San Francisco: Jossey-Bass.

Denzin, N. K., \& Lincoln, Y. S. (Eds.). (2003). Collecting and interpreting qualitative materials $\left(2^{\text {nd }}\right.$ ed.). Thousand Oaks, CA: Sage.

Dingerson, L., Miner, B., Peterson, B., \& Walters, S. (Eds.). (2008). Keeping the promise? The debate over charter schools. Milwaukee, WI: Rethinking Schools.

Dosdall, E. (2001). Edmonton's enterprise. School Administrator, 58(5), 6-11.

Edmonton public schools. (2007). Edmonton public school board website. Retrieved August 14, 2010, from http://www.epsb.ca

Gewirtz, S., Ball, S. J., \& Bowe, R. (1995). Markets, choice and equity in education. Philadelphia: Open University Press.

Guimont, G. (2003). French immersion in different settings: A comparative study of student achievement and exemplary practices in immersion centres versus dualand multi-track schools. Unpublished mMaster's thesis, University of Alberta, Edmonton, AB.

James, C. E. (2003). Seeing ourselves: Exploring race, ethnicity and culture ( $3^{\text {rd }}$ ed.) 
Toronto: Thompson.

Kymlicka, W. (1996). Social unity in a liberal state. Social Policy and Philosophy, 13, $105-136$.

Lamarre, N. (1995). The experiences of French immersion teachers in dual and multitrack schools in Alberta. Unpublished doctoral dissertation, University of Alberta, Edmonton, AB.

Lambert, W., \& Taylor, D. (1984). Language in the education of ethnic minority children in Canada. In R. J. Samuda, J. W. Berry, \& M. Laferrier (Eds.), Multiculturalism in Canada: Social and educational perspectives (pp. 210-215). Boston: Allyn \& Bacon.

Levine-Rasky, C. (2008). Middle-classness and whiteness in parents' responses to multiculturalism: A study of one school. Canadian Journal of Education, 31(2), 459-490.

Lund, D. E., \& Veinotte, C. (in press). Researching a social justice course in a charter school: A duoethnographic conversation. In Education: Exploring Our Connective Educational Landscape.

Moore, D., \& Davenport, S. (1989). The new improved sorting machine. Chicago: Designs for Change.

Nieto, S., \& Bode, P. (2007). Affirming diversity: The sociopolitical context of multicultural education ( $5^{\text {th }}$ ed.). New York: Allyn \& Bacon.

Sadava, M. (2010, September). More choice, less education. Alberta Views, 13, 26-30.

Sleeter, C., \& McLaren, P. (2009). Origins of multiculturalism. In W. Au (Ed.), Rethinking multicultural education: Teaching for racial and cultural justice (pp. 17-19). Milwaukee, WI: Rethinking Schools.

West, A. (2006). "Skimming the cream?" Admissions to charter schools in the United States and to autonomous schools in England. Educational Policy, 20(4), 615639.

Yin, R. (2003). Case study research: Design and methods ( $3^{\text {rd }}$ ed.). Thousand Oaks, CA: Sage. 